\title{
Social aspects of ethno-psychopharmacology: an Arab perspective
}

\author{
Tarek A. Okasha
}

Professor of Psychiatry, WPA Zonal Representative for North Africa, Institute of Psychiatry, Faculty of Medicine, Ain Shams University, 3 Shawarby Street, Kasr el Nil, Cairo, Egypt, email tokasha@internetegypt.com

S ome 7000 years ago Egyptians believed in one God, the after-world and that our worldly deeds would be balanced in the day of judgement. This led James Breasted to consider that the emergence of Egyptian culture marked the dawn of conscience (Breasted, 1934; Okasha \& Okasha, 2000).

As societies have become more diverse and the world evolves into a global village, the need to integrate culture into medicine and psychiatry becomes more critically important. Worldwide, increasing ease of international travel and migration and advances in information technology have enhanced the interaction and intermingling of people from different cultural and social systems. As a result, practitioners of health and mental health professionals are increasingly being called on to treat patients from backgrounds very different from their own.

In traditional cultures such as the Egyptian, the humanitarian interaction with a doctor is valued as much, if not more, than his or her technical ability or scientific knowledge. The humanitarian nature of this interaction depends on the way the doctor deals with the patient and his or her family, and the extent to which the doctor expresses respect for and acceptance of local cultural and spiritual norms.

In traditional cultures, social integration is emphasised more than autonomy; that is, the family, not the individual, is the unit of society. Dependence is more natural and infirmity is less alien in these cultures. When affiliation is more important than achievement, how one appears to others becomes vital, and shame, rather than guilt, becomes a driving force. In the same manner, physical illness and somatic manifestations of psychological distress become more understood and acceptable and evoke a caring response; in contrast, a vague complaint of psychological symptoms may be disregarded or be considered to indicate that the patient is 'soft' or, worse, 'insane'.

In some cultures, such as the Arab culture, the collectivity of the community is valued rather than the individuality of its members. Decisions are made not at an individual level, but at a familial, tribal or communal level, in the best perceived collective interest. How can we adhere to our ethical guidelines and at the same time not disregard the local values and norms of our target population? How can we practise without showing disrespect or disregard for local values? On the other hand, how can we ensure that respect for the local culture does not become a pretext for bypassing ethical guidelines to the detriment of our patients' rights (Okasha, 2000)?

Whether we like it or not, encounters between psychiatry and the law keep bringing us back to our conflicting conceptions of the value of health, on the one hand, and the value of liberty, integrity and autonomy, on the other. Culture, ethnicity and sometimes sociodemographic factors such as level of education, age and gender suggest different attitudes between cultures regarding the importance of patient autonomy and informed consent. What is the perceived harm when members of the medical community violate cultural conventions and insist on telling the truth to patients? In what ways and to what extent are the coping mechanisms of individuals and families disrupted? In what way does acculturation change the beliefs of patients of various ethnicities?

\section{Cross-cultural variation in attitudes to medical treatment}

To answer these questions, it may be helpful to consider how individuals interact in traditional societies, such as Arab culture. We may then be able to understand the challenges and difficulties involved in implementing guidelines such as the Declaration of Madrid on ethical standards for psychiatric practice (World Psychiatric Association, 1996).

One must first be familiar with the main characteristics that differentiate the position of the individual within his or her community in a traditional society from that in a Western society. Although societies should not be considered in a stereotypical framework, general common attitudes within societies can be assumed (Leff, 1988, p. 79).

Differences between two types of societies are listed in Table 1. It is not intended to imply that these characteristics are invariably true of such societies, nor that they are inflexible or stereotypical features.

When we look at expressed emotions and compare studies from traditional societies and from non-traditional societies, we find that the overall relapse rate in the study group in an Egyptian sample (a 'traditional' society) is 56\%, which is similar to the rates in studies from the UK and USA (considered 'non-traditional'), at 53\% and 58\%, respectively. The more a family is critical of the patient, the higher is the risk of relapse. The difference, however, lies in the determination of the best cut-off point separating high from low expressed emotion. In the English study (Vaughn \& Leff, 1976) two critical comments were enough for relapse, while in the US study (Hooly et al, 1986) three critical comments were necessary. However, in the Los Angeles study (Montero et al, 1992) six critical comments were needed and in the Egyptian study (Okasha et al, 1994) seven critical comments were needed. We notice from these studies that non-traditional societies 
Table 1 Differences between traditional and non-traditional societies regarding personal and professional relationships and their relevance to medical treatment

\begin{tabular}{|c|c|}
\hline Traditional societies & Non-traditional societies \\
\hline Family and group oriented & Individually oriented \\
\hline $\begin{array}{l}\text { Extended family } \\
\text { Status determined by age, }\end{array}$ & $\begin{array}{l}\text { Nuclear family } \\
\text { Status achieved by own efforts }\end{array}$ \\
\hline $\begin{array}{l}\text { position in family and care of } \\
\text { elderly }\end{array}$ & \\
\hline $\begin{array}{l}\text { Relationship between kin } \\
\text { obligatory }\end{array}$ & $\begin{array}{l}\text { Relationship between kin is a } \\
\text { matter of individual choice }\end{array}$ \\
\hline $\begin{array}{l}\text { Arranged marriage, with an } \\
\text { element of choice dependent } \\
\text { on inter-familial relationship }\end{array}$ & $\begin{array}{l}\text { Choice of marital partner, } \\
\text { determined by interpersonal } \\
\text { relationship }\end{array}$ \\
\hline $\begin{array}{l}\text { Extensive knowledge of distant } \\
\text { relatives' lives }\end{array}$ & $\begin{array}{l}\text { Knowledge of close relatives' } \\
\text { lives only }\end{array}$ \\
\hline Family decision-making & Individual autonomy \\
\hline External locus of control & Internal locus of control \\
\hline $\begin{array}{l}\text { Physician's decision respected } \\
\text { and revered; healthy doctor- } \\
\text { patient relationship }\end{array}$ & $\begin{array}{l}\text { Doubt and mistrust in doctor- } \\
\text { patient relationship }\end{array}$ \\
\hline Rare suing for malpractice & Common suing for malpractice \\
\hline to God'c mill & \\
\hline $\begin{array}{l}\text { Individual can be replaced; } \\
\text { family should continue and } \\
\text { pride is in family ties }\end{array}$ & $\begin{array}{l}\text { Individual is irreplaceable; pride } \\
\text { is in self }\end{array}$ \\
\hline $\begin{array}{l}\text { Pride in family care of patient } \\
\text { who is mentally ill }\end{array}$ & $\begin{array}{l}\text { Community care of patients who } \\
\text { are mentally ill }\end{array}$ \\
\hline $\begin{array}{l}\text { Dependence on God regarding } \\
\text { health and disease; illness and } \\
\text { recovery attributed to God }\end{array}$ & Self-determined recovery \\
\hline
\end{tabular}

After Okasha (2000)

like the USA and UK had similar results while Los Angeles, which has a very high Hispanic population, was similar to the Egyptian study, both considered traditional societies. It seems a disadvantage that little is known about the influence on patients' outcome of warmth and positive remarks or rather warmth versus critical comments in family life, especially in traditional societies.

Criticism may sometimes be taken as a sign of care, interest and love in an Egyptian enmeshed family (Okasha, 2000). High expressed emotion can be viewed as a kind of social trait in many Egyptian families and in many other traditional societies around the world.

\section{Cross-cultural variation due to genetic and other influences on drug metabolism}

Many factors affect response to medication, mainly genetic ones - for example, those determining the cytochrome P450 enzymes in the liver, which in turn affect drug metabolism - but also cultural ones. For example, $45 \%$ of Egyptians are smokers, with an average cigarette consumption rate per adult of 1201 per year; by way of comparison, in Greece it is 3230 and in Norway it is 739 (United National Development Programme, 2003). By way of a further example, most Arab populations consume large amounts of tea, whereas coffee is often drunk in European countries and the USA. Tea has a high content of tannic acid, which hinders the absorption of iron from the stomach and causes mild anaemia, which in turn may lead to problems such as dizziness, fatigue and exhaustion, which may be wrongly attributed as side-effects from medications.
Helminthic infections must also be taken into consideration. These include schistosomiasis (bilharziasis), which affects the function of the liver and can lead to cirrhosis, splenomegaly and portal hypertension. These disorders affect liver metabolism (Haslett et al, 2002).

Another important factor is the use, or rather misuse, of herbal medications with psychotropic drugs, which carries the potential of drug-drug interactions. These herbal medications are unfortunately available over the counter or are sold by street vendors in the markets in several Arab countries.

Other factors such as personality, locus of control, diet, lifestyle and family social support also play a role (Okasha, 1988; Ruiz, 2000).

\section{Conclusion}

The practice of psychiatry is at a crucial stage. None of the famous theories about the origins of psychiatric disorder which have appeared in the past century, from pure behavioural reflexology to elaborate psychodynamic formulations, has proved sufficient to describe in full the development and function of the human mind in health and disease. Our new hope seems to be in the synapse as the biological answer to the complexities of the mind. Pragmatic and convenient as they can be, such ideas are too simplistic to provide all the answers and solutions. It is time for reflection and perhaps our cultural heritage can help.

There is another reason to look more carefully at the contributions of different cultures: the creation of conditions for a better understanding among professionals. All of us need to know the realities of other cultures. Each culture has the potential to contribute to the advancement of our complex and multidimensional discipline. Knowing the contributions of another culture can also decrease some of the misunderstandings we have regarding other cultures (Mohit, 1999).

For those in charge of providing models of services, knowledge of cultural contributions is of great importance. It provides opportunities for designing services that are more acceptable to their users. It helps to decrease the stigma of psychiatric illness and potentially enhances the provision of more humane services. Finally, the interaction between culture, environment, biology and brain plasticity provides an anchor for aetiology, diagnosis and management of mental disorders.

Will our increasing knowledge about the genome and proteome clarify the ethnic, cultural and racial differences in response to psychiatric treatment, and help us to choose the most efficacious drug with the least side-effect profile, instead of our current trial and error approach? Will there come a day when any patient coming to the psychiatric clinic can undergo a simple blood test and, on the basis of the analysis, we can choose directly the most effective medication for the patient with the most advantageous trade-off between side-effects and clinical response?

\section{References}

Breasted, J. H. (1934) The Dawn of Conscience. Scriber's.

Haslett, C., Chilvers, E., Boom, N., et al (eds) (2002) Davidson's Principles and Practice of Medicine (19th edn). Churchill Livingstone.

Hooly, J. M., Orley, J. \& Teasdole, J. D. (1986) Levels of expressed 
emotion and relapse in depressed patients. British Journal of Psychiatry, 148, 642-647.

Leff, J. (1988) Psychiatry Around the Globe: A Transcultural View. Gaskell.

Mohit, A. (1999) Middle East culture: mental health and mental illness. In One World, One Language - Paving the Way to Better Perspectives for Mental Health (eds J. Lopez-Ibor, F. Lieh-Mak, H. Visotsky, et al). Hogrefe \& Huber.

Montero, I., Gomez-Beneyto, M., Ruiz, I., et al (1992) The influence of family expressed emotion on the course of schizophrenia in a sample of Spanish patients. British Journal of Psychiatry, 161, 217-222.

Okasha, A. (ed.) (1988) Okasha's Clinical Psychiatry. Anglo Egyptian Bookshop.

Okasha, A. (2000) The impact of Arab culture on psychiatric ethics. In Ethics Culture and Psychiatry. International Perspectives (eds A. Okasha, J. Arboleda-Florez \& N. Sartorius). American Psychiatric Press.

Okasha, A. \& Okasha, T. (2000) Notes on mental disorders in pharaonic Egypt. History of Psychiatry, 11, 413-424.
Okasha, A., El Akabawi, A., Synder, K., et al (1994) Expressed emotion, perceived criticism, and relapse in depression: a replication in an Egyptian community. American Journal of Psychiatry, 151, 1001-1005.

Ruiz, P. (ed.) (2000) Ethnicity and psychopharmacology. In Review of Psychiatry. Volume 19 (eds J. Oldham \& M. Riba). American Psychiatric Press.

United Nations Development Programme (2003) Human Development Report. Available at http://www.undp.org (last accessed 17 April 2007).

Vaughn, C. E. \& Leff, J. P. (1976) The influence of family and social factors on the course of psychiatric illness: a comparison of schizophrenic and depressed neurotic patients. British Journal of Psychiatry, 129, 125-137

World Psychiatric Association (1996) Declaration of Madrid on Ethical Standards for Psychiatric Practice. Approved by the General Assembly on 25 August 1996 and amended by the General Assembly in Yokohama, Japan, in August 2002. See http://wpanet.org/newhome/ about/ethic1.html (last accessed 17 April 2007).

\section{Psychiatry in Germany}

\section{Wolfgang Gaebel, Jürgen Zielasek and Ulrich Müller}

Department of Psychiatry and Psychotherapy, Heinrich-Heine-Universität, Rhineland State Clinics, Bergische Landstrasse 2, D-40629, Düsseldorf, Germany, email wolfgang.gaebel@uni-duesseldorf.de

ermany has an approximate area of $357000 \mathrm{~km}^{2}$. Its population is 82.526 million. The life expectancy at birth is 75.6 years for men and 81.6 years for women (World Health Organization, 2005). The proportion of gross domestic product allocated to the health budget is $10.8 \%$. The per capita total expenditure on health is $\$ 2820$ (international dollars here and below) and the per capita government expenditure on health is $\$ 2113$ (World Health Organization, 2005). A major factor in recent German history was reunification, which had a pronounced effect on the German healthcare system.

\section{History}

The term 'psychiatry' was coined by Johann Christian Reil in 1808. In the 19th century, German psychiatry began to develop into a scientific discipline under the influence of Wilhelm Griesinger (1817-68), who focused on a holistic but differentiated approach, covering biological and psychological methods. At the beginning of the 20th century, psychiatrists like Emil Kraepelin, Alois Alzheimer, Kurt Schneider and Carl Wernicke founded the basis of current psychiatric classification systems.

In the period of the National Socialists (1933-45), German psychiatry was partially instrumentalised for political purposes, especially for the programme of 'euthanasia'. This terrible period has been intensively analysed. The review by Seeman (2005) is a useful English introduction to this topic.
In the late 18th and early 19th century, large psychiatric institutions were founded, mainly outside the metropolitan areas. In the last part of the 20th century, the advent of psychopharmacotherapy and social psychiatry changed the picture of German psychiatry. Following the Psychiatrie Enquête report of 1975 (see under 'Mental health policy', below), many smaller psychiatric departments were set up in community hospitals but the total number of psychiatric hospital beds declined.

\section{Epidemiology}

The lifetime prevalence for any psychiatric disorder in Germany is $42 \%$ and the 12 -month prevalence rate is $31 \%$ for the adult population, not much different from the prevalence rate in the European Union (EU) as a whole, of $27 \%$ (Wittchen \& Jacobi, 2005). In Germany, only about 25\% of the population with a mental illness are in contact with mental health services, compared with $26 \%$ in the EU. Mental disorders are responsible for about $40 \%$ of all sick leave from work and $28 \%$ of all early retirements (Roth-Sackenheim, 2005). Mental disorders comprise the only growing group of disorders among all cases and days of sick leave in Germany, with an increase of approximately 70\% from 1994 to 2004 (DAK Gesundheitsreport, 2006).

There are about 55000 general practitioners in Germany. Given the 12-month prevalence rate of mental disorders in Germany of $31 \%$, there should be, annually, some 24 million 